\title{
Berichtigung zu Heft 16/1
}

Beim Beitrag von Ursula Klein (N.T.M. 16 (2008) Seiten 5-38) kam es durch ein Missverständnis in der Drucklegung zum bedauerlichen Verlust von wichtigen Quellenangaben. Die Redaktion bittet um Entschuldigung und erklärt hiermit, dass dieser Fehler nicht auf ein Verschulden der Autorin zurückgeht.

S. 24, 3. Absatz, 4. Zeile: Durch diese Erweiterung standen ab 1766 außer dem eigentlichen Laboratoriumsraum vier weitere Räume für die Aufbewahrung von Instrumenten, Gefäßen und Materialien zur Verfügung (ABBAW, I-XIII-20: Blätter 9-16).

S. 25, 1. Absatz, 3. Zeile: Seinem Brief ist eindeutig zu entnehmen, dass Marggraf das Akademielaboratorium weitgehend mit eigenen Geräten ausgestattet hatte, denn es heißt dort wörtlich: „Es ist aus dem Archiv der Academie zu ersehen, das alles was sich im Laboratorio befindet, ein weniges davon ausgenommen, von mir dahin gebracht worden sey." (ABBAW, I-XIII-20: Blatt 7)

S. 25, 3. Absatz, 5. Zeile: Im Unterschied zu den „philosophischen Instrumenten" der Zeit waren die chemischen Instrumente jedoch viel kostengünstiger, und auch die laufenden jährlichen Kosten des Laboratoriums waren mit rund 200 Reichstalern 1768 relativ niedrig (ABBAW I-XVI-134: Blätter 26, 29).

S. 26. 2. Absatz, 4. Zeile: Im April 1768 stellte die Ökonomische Kommission der Akademie ein umfassendes Inventarium „Über die in dem Königl. Preußischen Laboratorio befindliche Sachen an Instrumenten, Oefen und Praeparaten“ zusammen (ABBAW, I-XIII-20: Blätter 9-16).

S. 27, 2. Absatz, 3. Zeile: Unmittelbar an den eigentlichen Laboratoriumsraum grenzte ein Raum, der mit zahlreichen Regalen, Schränken und Tischen ausgestattet war und in dem verschiedene Gefäße, Chemikalien und unfertigen chemische Präparate („chymische Arbeiten, welche noch durchgesehen werden müssen“) aufbewahrt wurden (ABBAW, I-XIII-20: Blatt 14). 
S. 27, 2. Absatz, 16. Zeile: Das Inventarium listet hier Hunderte von gläsernen und irdenen Gefäßen auf, die von alltäglichen Gefäßen wie „Zucker Gläsern“, „Urin Gläsern“, „Milchnäpfen“ und „Florentiner Weinflaschen“ über Phiolen, Schmelztiegel und verschieden geformten Retorten und Destillationskolben bis zu einer "Maschine“ für die Verbrennung von Phosphor und einer für Destillationen an der Sonne reichen (ABBAW, I-XIII-20: Blätter 10, 11).

S. 27, 3. Absatz, 16. Zeile: Nicht um eine Zuckerextraktion im kleinen experimentellen Maßstab, sondern um die technologische Exploration der $\mathrm{Zu}$ ckergewinnung in der Größenordnung von Zentnern (ABBAW, I-XIII-26, Blatt 1, Müller 2002).

S. 28, 1. Absatz, 6. Zeile: In einem Brief wandte er sich an das „Königliche wohllöbliche akademische Direktorium“ mit der "dringende[n] Bitte, der schneunigenden Herstellung des im Argen liegenen academischen Hauses, in einen, der Ehre der Academie anständigen, bewohnbaren Zustand" (ABBAW, I-XIII-26: Blatt 11).

S. 28, 1. Absatz, 15. Zeile: Als vorläufige Lösung schlug Klaproth vor, „es kann daher fürs erste mein eigener Apparat nothdürftig hinreichend sein“ (ABBAW, I-XIII-26: Blätter 65, 66).

S. 28, 1. Absatz, 19. Zeile: Klaproths wiederholte Beschwerden führten schließlich zum Neubau eines Laboratoriumshauses, das er im Dezember 1802 mitsamt der Ausstattung aus seinem Apothekenlaboratorium beziehen konnte (ABBAW, I-XIII-26: Blatt 131).

S. 34: Quellenliste zu Beginn der Literaturangaben entfällt. 